\title{
Evidence that Subanesthetic Doses of Ketamine Cause Sustained Disruptions of NMDA and AMPA-Mediated Frontoparietal Connectivity in Humans
}

\author{
Suresh D. Muthukumaraswamy, ${ }^{1}$ Alexander D. Shaw, ${ }^{2}$ ㄴaura E. Jackson, ${ }^{3}$ Judith Hall, ${ }^{3}$ Rosalyn Moran, ${ }^{4}$ \\ and Neeraj Saxena ${ }^{3,5}$ \\ ${ }^{1}$ Schools of Pharmacy and Psychology, The University of Auckland, Auckland 1142, New Zealand, ${ }^{2}$ Cardiff University Brain Research Imaging Centre, \\ Cardiff University, Cardiff CF103AT, United Kingdom, ${ }^{3}$ Department of Anaesthetics, Intensive Care and Pain Medicine, Cwm Taf University Health Board, \\ Llantrisant CF72 8XR, United Kingdom, ${ }^{4}$ Virginia Tech Carilion Research Institute, Bradley Department of Electrical and Computer Engineering, Roanoke, \\ Virginia 24016, and 5Department of Anaesthetics, Intensive Care and Pain Medicine, School of Medicine, Cardiff University, Cardiff CF144XW, \\ United Kingdom
}

Following the discovery of the antidepressant properties of ketamine, there has been a recent resurgence in the interest in this NMDA receptor antagonist. Although detailed animal models of the molecular mechanisms underlying ketamine's effects have emerged, there are few MEG/EEG studies examining the acute subanesthetic effects of ketamine infusion in man. We recorded 275 channel MEG in two experiments ( $n=25$ human males) examining the effects of subanesthetic ketamine infusion. MEG power spectra revealed a rich set of significant oscillatory changes compared with placebo sessions, including decreases in occipital, parietal, and anterior cingulate alpha power, increases in medial frontal theta power, and increases in parietal and cingulate cortex high gamma power. Each of these spectral effects demonstrated their own set of temporal dynamics. Dynamic causal modeling of frontoparietal connectivity changes with ketamine indicated a decrease in NMDA and AMPA-mediated frontal-to-parietal connectivity. AMPA-mediated connectivity changes were sustained for up to $50 \mathrm{~min}$ after ketamine infusion had ceased, by which time perceptual distortions were absent. The results also indicated a decrease in gain of parietal pyramidal cells, which was correlated with participants' self-reports of blissful state. Based on these results, we suggest that the antidepressant effects of ketamine may depend on its ability to change the balance of frontoparietal connectivity patterns.

Key words: alpha rhythms; depression; dynamic causal modelling; gamma rhythms; ketamine; magnetoencephalography

\section{Significance Statement}

In this paper, we found that subanesthetic doses of ketamine, similar to those used in antidepressant studies, increase anterior theta and gamma power but decrease posterior theta, delta, and alpha power, as revealed by magnetoencephalographic recordings. Dynamic causal modeling of frontoparietal connectivity changes with ketamine indicated a decrease in NMDA and AMPAmediated frontal-to-parietal connectivity. AMPA-mediated connectivity changes were sustained for up to 50 min after ketamine infusion had ceased, by which time perceptual distortions were absent. The results also indicated a decrease in gain of parietal pyramidal cells, which was correlated with participants' self-reports of blissful state. The alterations in frontoparietal connectivity patterns we observe here may be important in generating the antidepressant response to ketamine.

\section{Introduction}

The now widely replicated observation that a single subanaesthetic dose of ketamine can have rapid antidepressant effects

Received March 8, 2015; revised July 8, 2015; accepted July 20, 2015.

Author contributions: S.D.M., A.D.S., J.H., and N.S. designed research;S.D.M., A.D.S., L.E.J., and N.S. performed research; S.D.M. and R.M. contributed unpublished reagents/analytic tools; S.D.M. and R.M. analyzed data; S.D.M., A.D.S., and N.S. wrote the paper.
(Berman et al., 2000; Zarate et al., 2006b; Murrough et al., 2013) has caused a re-evaluation of the neurobiology of major depressive disorder. Although it is unclear whether ketamine could be safely adopted for general clinical practice (Krystal et al., 2013; Rush, 2013), ketamine's rapid efficacy highlights the importance of glutamatergic systems in major depression and at the same

This work was supported by the MRC/EPSRC funded UK MEG Partnership Grant MR/K005464/1, and S.D.M. is supported by a New Zealand Royal Society Rutherford Discovery Fellowship. 
time serves as a useful interventional compound for studying the molecular basis of depression.

Used as both an anesthetic and drug of abuse, the phencyclidine derivative ketamine has a "rich" pharmacology: in addition to its principal mechanism of action as a noncompetitive antagonist of NMDA receptors, it exhibits action at muscarinic, $\sigma$, $\mu$-opioid receptors, and $\alpha$ and $\beta$ adrenergic receptors; and blocks HCN1 channels as well as the serotonin and norepinephrine transporters (Bergman, 1999; Chen et al., 2009; Stahl, 2013). Despite this multitude of effects, animal models suggest that the antidepressant actions of ketamine are mediated by its antagonism of NMDA receptors. According to these models, blockade of NMDA receptors by ketamine results in increased AMPAmediated glutamatergic signaling, which in turn triggers the activation of intracellular synaptogenic pathways (Li et al., 2010; Autry et al., 2011). This activation includes an increase in the mTOR signaling pathway, which is necessary for the antidepressant response (Li et al., 2010). It is possible that ketamine modulates neurotransmission through additional pathways given the failure of the antagonist memantine to generate anti-depressant effects (Zarate et al., 2006a). However, NMDA-mediated effects are important as evidenced by positive antidepressive effects with gaseous nitrous oxide (Nagele et al., 2015) and AZD-6765 (Sanacora et al., 2014), both NMDA antagonists. It has been demonstrated with MEG that patients who respond to ketamine exhibit enhanced sensory evoked responses providing evidence in humans that synaptic potentiation may mediate the antidepressant response to ketamine (Cornwell et al., 2012).

A number of brain imaging studies demonstrate that major depressive disorder is characterized by hyperactivity in the brain's default mode network (Greicius et al., 2007; Sheline et al., 2009), whose major hubs include the medial prefrontal and posterior cingulate/precuneus cortices (Andrews-Hanna et al., 2010). It has been suggested that antidepressants may work in part by reducing activity in this network (Posner et al., 2013; Wang et al., 2015), and indeed one study has shown that subanesthetic ketamine infusion reduces default mode network activity in healthy participants $1 \mathrm{~d}$ after administration. Several MEG studies have demonstrated that patients with lowest task-based connectivity and activity in the anterior cingulate cortex show the largest antidepressant response to ketamine (Salvadore et al., 2009, 2010). These studies again highlight importance of connectivity alterations in depression and moreover the usefulness of MEG as a tool to probe electrophysiological connectivity in the context of ketamine and depression.

Based on these facts, in the present studies we hypothesized that during subanesthetic ketamine administration there would be a rapid reduction in frontoparietal connectivity. To quantify connectivity we combined MEG recordings of resting-state oscillatory activity with dynamic causal modeling (DCM) estimates of effective connectivity, and used a crossover design with subanesthetic ketamine and saline infusions. In DCM, biologically plausible biophysical models are fit to empirical data to allow estimates of synaptic responses within specified neuronal ensembles (Moran et al., 2011b), the effective connectivity between ensembles in interconnected brain regions (Friston et al., 2012), and how these connectivity pa-

The authors declare no competing financial interests.

Correspondence should be addressed to Dr Suresh Muthukumaraswamy, School of Pharmacy, The University of Auckland, Private Bag 92019, Auckland, New Zealand. E-mail: sd.muthu@auckland.ac.nz.

DOI:10.1523/JNEUROSCI.0903-15.2015

Copyright $\odot 2015$ the authors $\quad 0270-6474 / 15 / 3511695-13 \$ 15.00 / 0$ rameters are altered under pharmacological challenge (Moran et al., 2015). Thus, DCM provides a potentially powerful translational bridge between animal models and human neurophysiology, where these parameters are not directly measurable. Here, we used source reconstruction to estimate the activity from two principal hubs of the default mode, the medial prefrontal cortex and the precuneus, and estimated the changes in effective connectivity within and between these regions during and after ketamine infusion.

\section{Materials and Methods}

\section{Experiment 1}

Participants and experimental procedure. Experiment 1 included 19 healthy male participants (mean age $=25.8$ years, range $=19-39$ ). All participants gave informed consent to participate in the study, which was approved by a UK National Health Service research ethics committee. Volunteer exclusion criteria included any current or previous psychiatric disorder, determined with the Mini-International Neuropsychiatric Interview (MINI), current recreational or prescription drug use, contraindications for MEG/MRI, and needle phobia. Inclusion criteria for participation were that volunteers be of age 18-45, nonsmokers, American Society of Anesthesiologists Physical Status 1, and have a body mass index of $18-30 \mathrm{~kg} / \mathrm{m}^{2}$.

Participants underwent two scans on separate days, one using a placebo saline infusion and one using ketamine. In each scan session, 5 min of resting MEG was recorded, and then infusion commenced. Each participant received an initial bolus of $0.25 \mathrm{mg} / \mathrm{kg}$ delivered over $\sim 1 \mathrm{~min}$, followed by maintenance infusion at a rate of $0.375 \mathrm{mg} / \mathrm{kg} / \mathrm{h}$. Ten minutes of resting MEG were recorded following the start of the infusion. At this point, participants were asked to provide a rating of their subjective "high" on a scale between 0 and 40, using a two-digit button box. Measures of saccadic eye movement velocity were then taken. After this, participants commenced a series of tasks, data for which are reported previously (Shaw et al., 2015).

$M E G$ recordings. For the MEG recordings, participants lay in supine position. Participants' pulse rate and blood oxygenation level were continually monitored throughout the experiment via a probe over their left hand index finger with the intravenous cannula inserted on the back of the left wrist. Participants' wore a nasal cannula attached to medical oxygen, which was to be used in case of an emergency.

Whole-head MEG recordings were made using a CTF 275-channel radial gradiometer system sampled at $1200 \mathrm{~Hz}(0-300 \mathrm{~Hz}$ bandpass). An additional 29 reference channels were recorded for noise cancellation purposes and the primary sensors were analyzed as synthetic third-order gradiometers (Vrba and Robinson, 2001). Three of the 275 channels were turned off due to excessive sensor noise. In addition to the MEG channels, we recorded participants' ECG: horizontal and vertical electrooculograms (EOG), as well as electromyograms (EMG) from bilateral frontalis and temporalis muscles. Monocular pupilometry data were obtained using an iViewX-MEG system (SensoMotoric Instruments) sampled at $250 \mathrm{~Hz}$.

Data preprocessing. All MEG recordings were initially high-pass filtered at $1 \mathrm{~Hz}$, and segmented into epochs of $2 \mathrm{~s}$ in length (450 epochs with 150 preinfusion). Each epoch was then visually inspected, and those with gross artifacts (e.g., head movements, jaw clenches) were removed from the analysis. An automated algorithm was used to remove further epochs contaminated with muscle artifacts. In this algorithm, a set of 30 gradiometer sensors were predefined at the edge of the MEG dewar, as these are most likely to be contaminated by muscle artifacts (Muthukumaraswamy, 2013). Using Hanning-windowed Fourier transformations, we calculated the mean spectral power for these sensors in the $105-145 \mathrm{~Hz}$ frequency band (Muthukumaraswamy, 2013) for each epoch. If the resulting power averaged across these sensors exceeded $10 \mathrm{fT}^{2}$ then that epoch was eliminated from subsequent analysis On the remaining epochs we then performed independent component analysis (ICA) as implemented in Fieldtrip/EEGLAB (Delorme and Makeig, 2004) to identify and remove ocular, muscular and cardiac artifacts from the data. Any components that showed a correlation $(r>0.10)$ in the time domain 

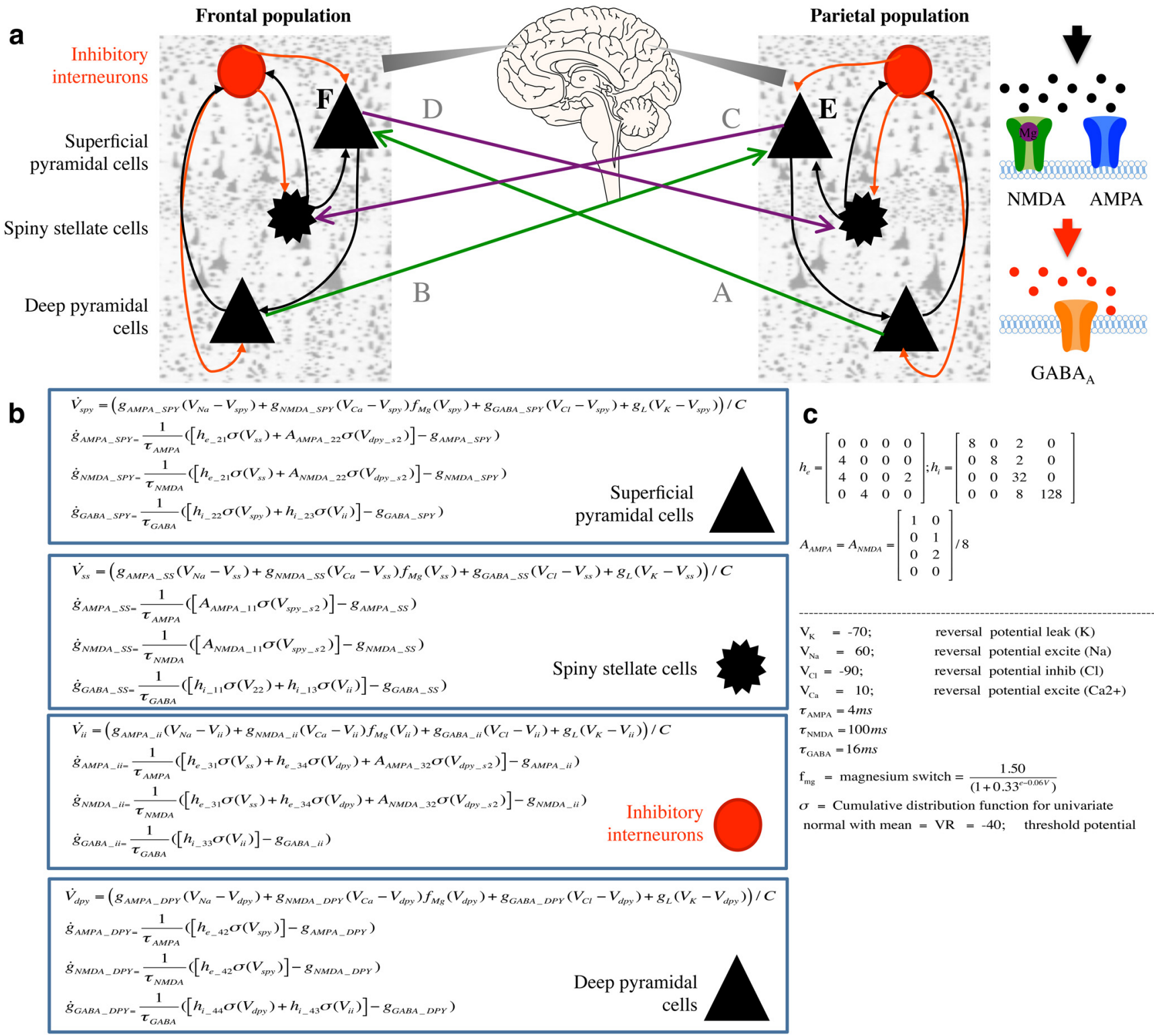

Figure 1. a Construction of the neural mass model from the winning model tested (Model 3). Two connected neural masses comprised the winning model, each with four subpopulations of neurons (superficial pyramidal cells, deep pyramidal cells, spiny stellate cells, and inhibitory interneurons). Intrinsic to each mass, excitatory connections are illustrated with black arrows, and intrinsic inhibitory connections are represented with red arrows. Right, Intrinsic excitatory connections are mediated by two excitatory receptor types (AMPA and NMDA), whereas intrinsic inhibitory connections use $\mathrm{GABA}_{A}$ receptors. Each receptor type is furnished with its own time constants and dynamics, and in the case of NMDA receptors, this includes the nonlinear behavior caused by a voltage-gated magnesium ion block. Each population of cells also contains an intrinsic gain parameter. In Model 3, between-region connectivity was modeled as lateral connections (nonhierarchical; Felleman and Van Essen, 1991; David et al., 2006) with full reciprocal connections between regions (Kobayashi and Amaral, 2003, 2007; Andrews-Hanna et al., 2010). Connections arise from both superficial and deep pyramidal cells and transmit to layer IV and layers I-III, respectively. Empirical data used for each population was derived from virtual sensors in the prefrontal cortex and precuneal areas of each participant. To explain differences between preketamine and postketamine infusion cross-spectral densities, we allowed six parameters to exhibit modulation by ketamine; NMDA mediated frontal and posterior connectivity, AMPA mediated frontal and posterior connectivity and a gain parameter (representing the excitability) for each mass (E, F). $\boldsymbol{b}$, Equations used in the generation of model dynamics with key parameter priors and implementation of the voltage gate on the NMDA receptor (Durstewitz et al., 2000) given in $\boldsymbol{c}$. This model is the standard cmm_nmda model implemented in the spm_fx_cmm_nmda.m file, freely available in the spm12 software (http://www.fil.ion.ucl.ac.uk/spm/).

with the EOG/EMG electrodes were automatically removed. Likewise, any components that showed correlations $(r>0.10)$ with similarly filtered EOG/EMG channels after being bandpass filtered in the range 105$145 \mathrm{~Hz}$ were removed. Visual inspection was also used to remove artifact components. All subsequent analyses were performed on the ICA cleaned datasets.

Frequency analysis: sensor space. Using the FieldTrip toolbox (Oostenveld et al., 2011) we converted our MEG data to planar gradient configuration, and then conducted a frequency analysis of the individual vector directions. Frequency analysis was conducted using Hanning windowed fast Fourier transforms between 1 and $100 \mathrm{~Hz}$ at $0.5 \mathrm{~Hz}$ frequency inter- vals and then the planar directions combined to give local maxima under the sensors. Analysis of sensor-level MEG data in a planar gradient (spatial-derivative) configuration has the advantage of easy interpretability, because field maps can be interpreted as having a source directly underneath field maxima (Bastiaansen and Knösche, 2000). For statistical analysis, we divided individual spectra into the following frequency bands: delta $(1-4 \mathrm{~Hz})$, theta $(4-8 \mathrm{~Hz})$, alpha $(8-13 \mathrm{~Hz})$, beta $(13-30$ $\mathrm{Hz})$, low gamma $(30-49 \mathrm{~Hz})$, and high gamma (51-99 Hz; Muthukumaraswamy et al., 2013). The preintervention baseline spectra were subtracted from each postintervention spectra and the differences between intervention and placebo tested using permutation testing of $t$ statistics at 
a
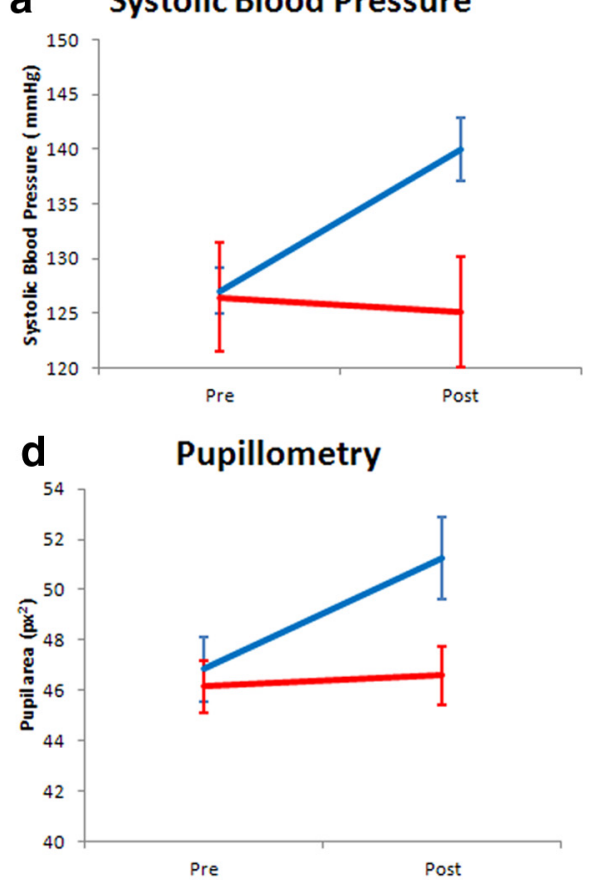

b

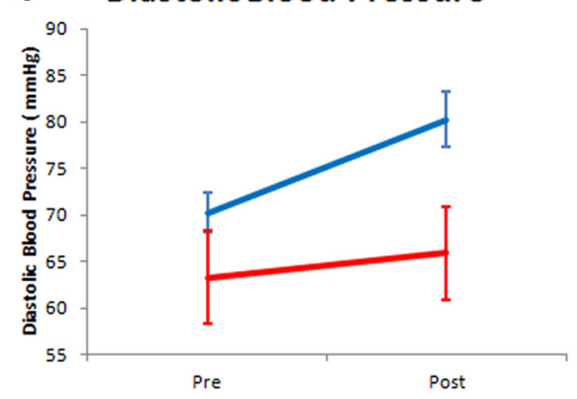

e

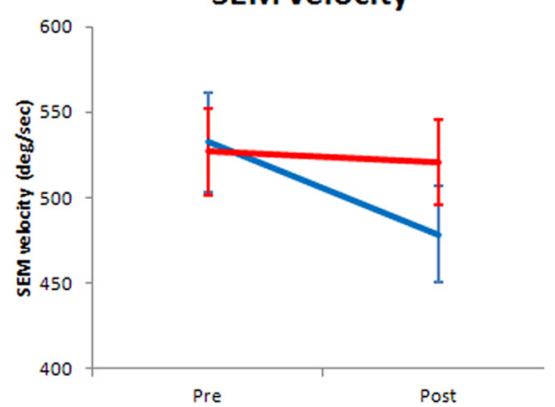

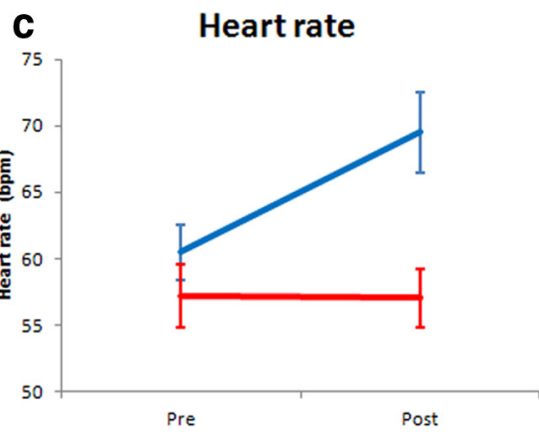

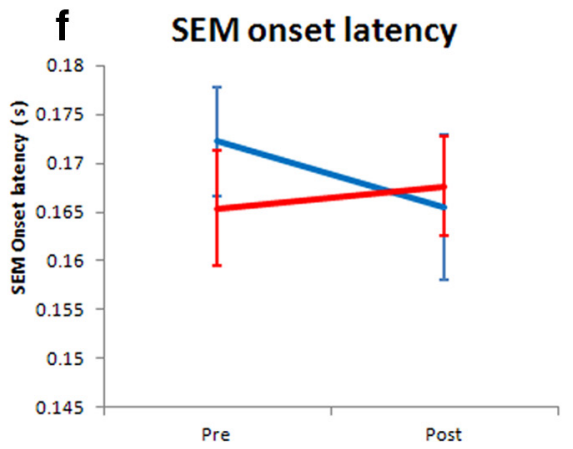

Figure 2. Basic physiological measures before and after infusion of either ketamine or placebo. Blue is ketamine; red is placebo. $\boldsymbol{a}-\boldsymbol{c}$, As expected participants demonstrated significant increases in systolic $\left(F_{(1,18)}=23.7, p<0.001\right)$ and diastolic $\left(F_{(1,18)}=12.1, p=0.003\right)$ blood pressure, as well as heart rate $\left(\left(F_{(1,18)}=16.0, p<0.001\right)\right.$. $d-f$, Participants also showed standard physiological responses of sedation, including increases in pupil diameter $\left(F_{(1,18)}=27.1, p<0.001\right)$ and saccadic eye movement $(S E M)$ velocity $\left(F_{(1,18)}=6.83, p<0.02\right)$, but not saccadic eye movement onset latency $\left(F_{(1,18)}=0.39, p=0.34\right)$. After the $10 \mathrm{~min}$ MEG recording following the onset of infusion, the mean subjective intensity rating of participants was $13.2 / 20(\mathrm{SE}=1.08)$ compared with 0 after placebo. Error bars are the standard error of the mean.

each postintervention time point (Nichols and Holmes, 2002; Maris and Oostenveld, 2007). The Type 1 error rate was controlled using cluster randomization analysis with an initial cluster-forming threshold of $p=$ 0.05 repeated $>5000$ permutations. The same spectral analysis technique was applied to the EMG channels in the $55-95 \mathrm{~Hz}$ band to check for possible muscle artifact contamination and to the EOG channels in the 1-20 Hz band to check for possible ocular artifacts.

Source localization. To localize drug-induced changes in oscillatory power, we used the beamformer algorithm synthetic aperture magnetometry (SAM; Robinson and Vrba, 1999). Global covariance matrices were calculated for the following six bandpass-filtered versions of the datasets: delta $(1-4 \mathrm{~Hz})$, theta $(4-8 \mathrm{~Hz})$, alpha $(8-13 \mathrm{~Hz})$, beta $(13-30$ $\mathrm{Hz})$, low gamma $(30-49 \mathrm{~Hz})$, and high gamma $(51-99 \mathrm{~Hz})$. Based on these covariance matrices, using the beamformer algorithm, a set of beamformer weights was computed for all voxels in the brain at $4 \mathrm{~mm}$ isotropic voxel resolution. A multiple local-spheres (Huang et al., 1999) volume conductor model was derived by fitting spheres to the brain surface extracted by the FSL Brain Extraction Tool (Smith, 2002). For SAM imaging, virtual sensors were constructed at each beamformer voxel and Student's $t$ images of source power changes computed for postinfusion versus preinfusion epochs. Volumetric group statistical analyses were conducted as previously described (Muthukumaraswamy et al., 2013). Five thousand permutations were calculated for each statistical test conducted with a $5 \mathrm{~mm}$ Gaussian smoothing kernel applied to the variance maps. We computed a paired $t$ test for the ketamine versus placebo images to reveal the drug interaction effect: $t$ images were thresholded at $p=0.05$ (cluster corrected).

Dynamic causal modeling of effective connectivity. Based on the results, we selected two regions-of-interest within the typical default-mode regions, for connectivity analysis. These were extracted from virtual sensors derived from local maxima in individual source localization images. Maxima were selected at image peaks near the medial prefrontal cortex showing increases in theta activity, and near parietoccipital cortex showing alpha power reductions. Cross-spectral densities were estimated for 1-45 Hz for both preinfusion and postinfusion avoid any contamination of subsequent modeling with $(50 \mathrm{~Hz})$ line noise artifacts. These spectral densities formed the data features of our connectivity analysis. DCM uses a biophysical model of neuronal responses based on neural mass models (David et al., 2006) to predict electrophysiological data. The neural mass model we used (Fig. 1a) was comprised of four populations of neurons (superficial pyramidal cells, deep pyramidal cells, spiny stellate cells, and inhibitory interneurons). Intrinsic (within area) excitatory connections are mediated by two excitatory receptor types, AMPA and NMDA and intrinsic inhibitory connections use $\mathrm{GABA}_{\mathrm{A}}$ receptors. Each receptor type is furnished with its own time constants and dynamics (Fig. 1b,c). In the case of NMDA-mediated receptor activity, this is additionally controlled by a nonlinear sigmoid to reflect the voltage-dependent magnesium ion block. Extrinsic (between area) connections are mediated by two connection types: "feedforward" connections, which project from superficial pyramidal cells to stellate cells, and "feedback" connections, which project from deep pyramidal neurons to superficial layers (interneurons and superficial pyramidal cells). We initially tested three models of extrinsic connectivity (see Results) using data from all participants and compared the log model evidences to determine the most likely model. To constrain the parameter set, we specified a set of four connectivity parameters that could potentially be modulated by ketamine: AMPA-mediated frontal-to-parietal connectivity, NMDA-mediated frontal-to-parietal connectivity, AMPA-mediated parietal-to-frontal connectivity, and NMDA-mediated parietal-tofrontal connectivity. We further specified a gain parameter for each neuronal subpopulation to account for within ensemble changes in excitability. These gain parameters are "lumped" parameters that encapsulate a variety of potential gain-control mechanisms, including both NMDA and non-NMDA mediated effects of ketamine. All DCM analyses used conductance-based neural mass models as implemented in the "cmm_nmda" model available in the spm12 (http://www.fil.ion.ucl.ac. $\mathrm{uk} / \mathrm{spm} /$ ) software. The generative models were then inverted (fitted to each individual's prefrontal and parietal responses) to obtain posterior densities over connectivity and gain parameters, initializing the parameter estimates with those obtained from the grand-average analysis. Spe- 


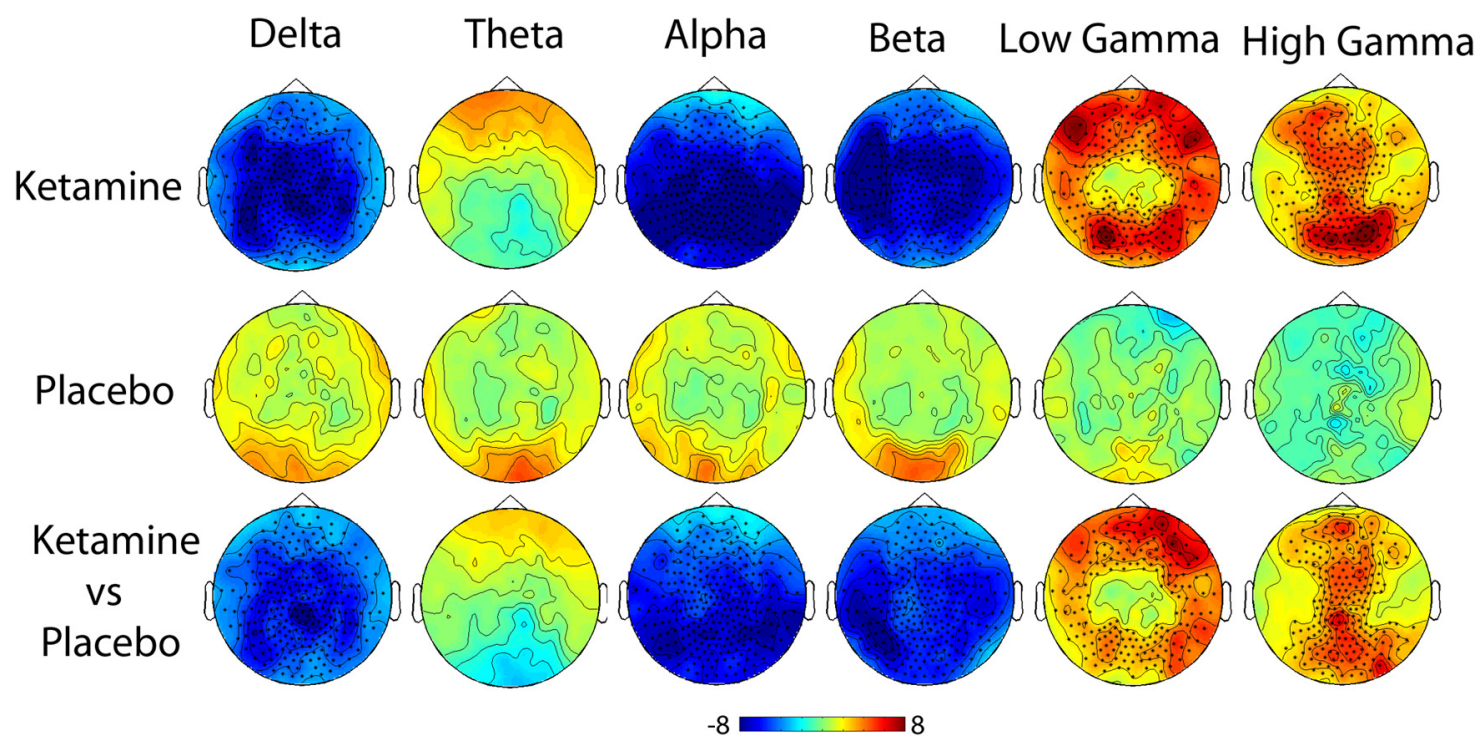

Figure 3. Statistical analysis of planar gradiometer configured MEG data for ketamine and placebo. Spectra for preinfusion data recordings were subtracted from the postinfusion data and then contrasts performed. Red indicates relatively more power following the drug and blue indicates relatively less power. Units are tstatistics. Significant sensor clusters are marked such that dark circles correspond to $p<0.01$ and crosses to $p<0.05$.

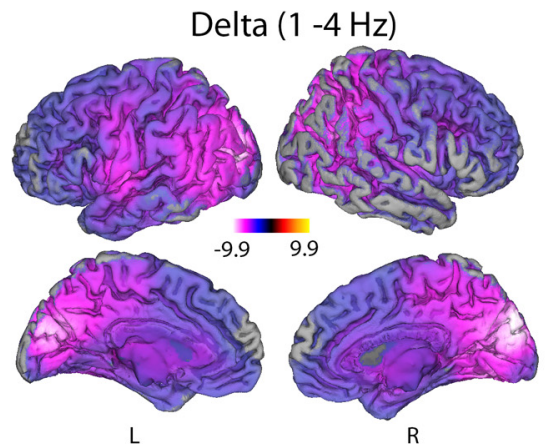

Beta $(13-30 \mathrm{~Hz})$

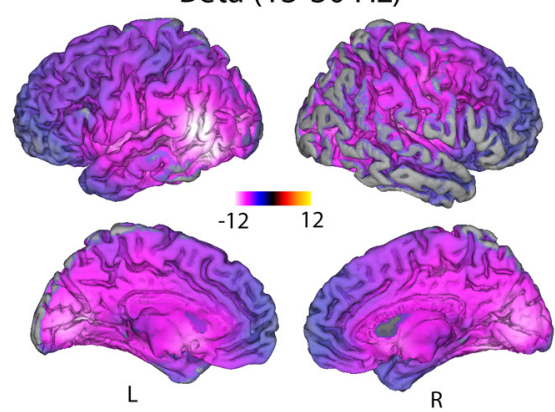

Theta $(4-8 \mathrm{~Hz})$

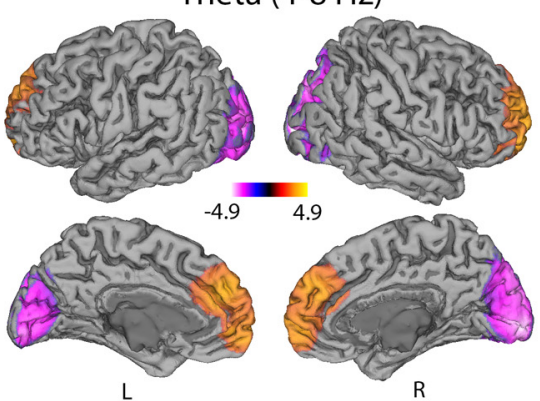

Low Gamma $(30-49 \mathrm{~Hz})$

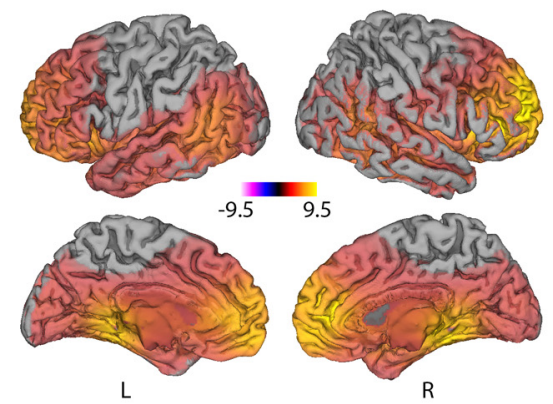

Alpha $(8-13 \mathrm{~Hz})$

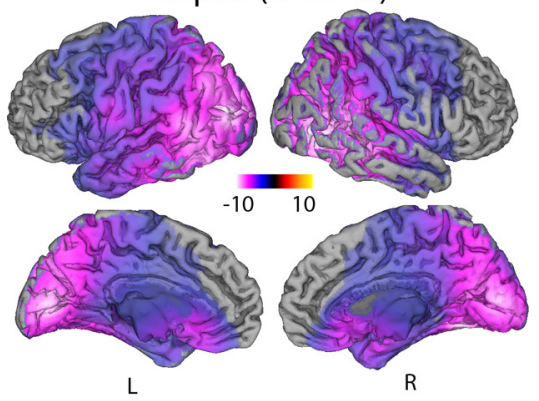

High Gamma $(51-99 \mathrm{~Hz})$

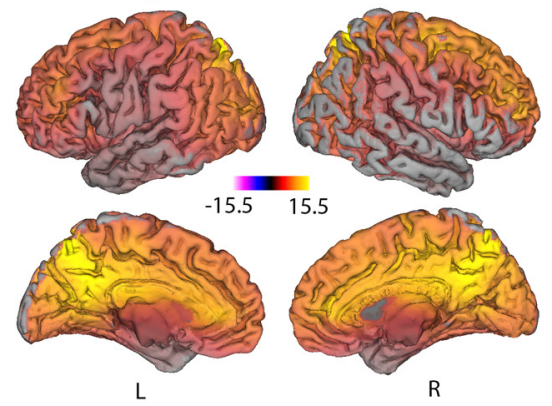

Figure 4. Statistical parametric maps showing the locations of significant $(p<0.05$, corrected) changes in source oscillatory power in the six frequency bands that span from 1 to $99 \mathrm{~Hz}$. Contrasts of spectral power represent the difference of ketamine after-and-before infusion versus placebo after-and-before infusion. Red colors represent increases in source power and yellow colors represent decreases.

cifically, a variational Bayesian scheme (variational Laplace) was used to approximate the posterior density over parameters by maximizing the negative free energy, a bound on the log-model evidence (Friston et al., 2007; Moran et al., 2011a).

Independent component network analysis of functional connectivity. For analysis of functional connectivity, agnostic to cell type or synaptic mechanisms, we also used the methodology described by Brookes et al. (2011) and in our previous work (Muthukumaraswamy et al., 2013). For each participant and frequency band, beamformer weights were computed on an $8 \mathrm{~mm}$ grid and beamformer time courses were then generated at every voxel and normalized by an estimate of the projected noise amplitude at that voxel. The Hilbert transform was applied to each voxel time course and the absolute value computed to generate an amplitude envelope of the oscillatory signals in each frequency band. The data at each voxel was down-sampled to an effective sampling rate of $1 \mathrm{~Hz}$, transformed to standard (MNI) space using FLIRT in FSL and data from all subjects were concatenated in the time dimension across subjects. Temporal ICA was applied to the concatenated datasets (separately for all six frequency bands) using the fast-ICA algorithm. Prewhitening was applied to reduce the dimensionality of the source space Hilbert envelope signals to 20 principal components before ICA (Hyvärinen and Oja, 2000; Brookes et al., 2011; Hall et al., 2013). Fifteen independent components were derived for each frequency band. From these components we identified those that matched previous reports (Brookes et al., 2011). 
For the identified components, we computed the SD of the component time course for each subject and condition. Differences in SD of the independent component time course between placebo and ketamine were assessed using $t$ tests using a Bonferroni correction value of 15 .

\section{Experiment 2}

Participants and experimental procedure. Experiment 2 included six healthy male participants (mean age $=27.2$ years, range $=20-36$ ) subject to the same exclusion/inclusion criteria as Experiment 1. In Experiment 2, 10 min of resting MEG was recorded, then infusion commenced with a bolus of $0.25 \mathrm{mg} / \mathrm{kg}$. This was followed by $20 \mathrm{~min}$ of maintenance infusion $(0.375 \mathrm{mg} / \mathrm{kg} / \mathrm{h})$. MEG was recorded continuously for a further $50 \mathrm{~min}$, making the sessions $80 \mathrm{~min}$ long in total. Participants were asked to lie still, with their eyes open and provide a rating of their subjective "high" on a scale between 0 and 40 at 2 min intervals using a two-digit button box.

$M E G$ recordings and data preprocessing. Identical to Experiment 1, except here there were 2400 epochs (300 preinfusion). Epochs contaminated with activity from the button press were excluded (10 seconds of every $2 \mathrm{~min}$ ).

Source localization, virtual sensor generation, and pharmacodynamics. For Experiment 2, the same preprocessing and source analysis steps were used to identify regions-of-interest in the early time window of ketamine infusion. In addition to the two regions identified in Experiment 1, a third parietal gamma source was identified. The location of this source was somewhat variable in individuals and frequently spatially overlapped with the alpha power change locations. Based on the identified regions of interest, we mapped the temporal evolution of power by generating the band-limited power in 2 min time bins (between-subjective ratings) for the entire $80 \mathrm{~min}$. To map the time course of DCM parameter changes in in the experiment we took the same two functional regions (posterior alpha/ prefrontal theta) and applied the winning connectivity model from Experiment 1 (Model 3). We divided the $70 \mathrm{~min}$ postrecording into seven, 10 min time windows and extracted the six parameters as in Experiment 1 for each time window. To relate the time course of DCM parameters to the spectral evolution of power a general linear model approach was used to control for within participant effects.

\section{Results}

\section{Experiment 1}

As a quality check of our in-scanner infusions, consistent with known physiological effects, ketamine caused increases in heart rate, blood pressure, and pupil diameter, and decreases in saccadic eye-movement velocity, indicative of sedation (Fig. 2). Similarly, participants' post hoc reports revealed large perturbations from normal consciousness as assessed with the 5D-ASC (Dittrich, 1998; Studerus et al., 2010); participants reported subjective states of disembodiment, hallucinations, and blissful feelings.

Estimates of ketamine-induced spectral changes were performed in both sensor space (Fig. 3) and source space (Fig. 4) using the beamformer source localization technique SAM. Both these figures display the contrast of ketamine after-versus-before infusion compared with placebo after-versus-before infusion with the peak spatial locations from the source localization presented in Table 1. Comparison of Figures 3 and 4 reveal highly consistent spatial patterns of power changes with decreases in source power seen in the delta (1-4 $\mathrm{Hz})$, posterior theta $(4-8 \mathrm{~Hz})$, alpha $(8-13 \mathrm{~Hz})$, and beta $(13-30$ $\mathrm{Hz})$ frequency bands. Conversely, in anterior theta $(4-8 \mathrm{~Hz})$, low $(30-49 \mathrm{~Hz})$, and high gamma $(51-99 \mathrm{~Hz})$ bands, increases in source power were seen.

We performed spectral analysis of the peripheral EOG and EMG channels that we recorded in Experiment 1. These analyses (Fig. 5) revealed that the anterior theta frequency power increases were not due to differential eye movement patterns. Similarly, we confirmed that the increases in gamma-band activity were not
Table 1. Local maxima of source power changes (Talairach coordinates) corresponding to the images in Figure 4

\begin{tabular}{|c|c|c|c|c|}
\hline & $x$ & $Y$ & $Z$ & $t$ \\
\hline \multicolumn{5}{|l|}{ Delta } \\
\hline Cuneus (R) & 11 & -87 & 31 & -9.98 \\
\hline Middle occipital gyrus (R) & -25 & -87 & 17 & -9.92 \\
\hline Lingual gyrus (R) & 19 & -67 & -5 & -8.47 \\
\hline Angular gyrus (R) & 53 & -61 & 33 & -8.21 \\
\hline Superior parietal lobule (R) & 29 & 67 & 53 & -7.92 \\
\hline Inferior parietal lobule (R) & 49 & 51 & 53 & -7.44 \\
\hline Superior temporal gyrus $(\mathrm{L})$ & -47 & -11 & 7 & -7.27 \\
\hline Middle occipital gyrus (L) & -45 & -67 & -17 & -7.24 \\
\hline Superior parietal lobule (L) & -13 & -59 & 63 & -6.69 \\
\hline Insula (R) & 43 & -17 & 13 & -6.46 \\
\hline Inferior frontal gyrus (L) & -35 & 31 & 3 & -5.68 \\
\hline Middle temporal gyrus (R) & 43 & -1 & -33 & -5.08 \\
\hline Inferior frontal gyrus (R) & 49 & 37 & -17 & -4.32 \\
\hline \multicolumn{5}{|l|}{ Theta } \\
\hline Middle occipital gyrus (R) & 21 & -97 & 3 & -4.91 \\
\hline Middle occipital gyrus (L) & -19 & -95 & 1 & -4.30 \\
\hline Superior frontal gyrus (L) & -9 & 61 & -7 & 3.71 \\
\hline Medial frontal gyrus (L) & -3 & 45 & 29 & 3.62 \\
\hline Superior frontal gyrus (R) & 23 & 65 & -5 & 3.58 \\
\hline \multicolumn{5}{|l|}{ Alpha } \\
\hline Cuneus (L) & -17 & -81 & 17 & -10.0 \\
\hline Middle occipital gyrus (R) & 49 & -71 & 3 & -9.60 \\
\hline Middle temporal gyrus (R) & 57 & -39 & -3 & -8.93 \\
\hline Middle occipital gyrus (L) & -47 & -71 & -13 & -8.67 \\
\hline Middle temporal gyrus (L) & -47 & -53 & 5 & -8.65 \\
\hline Superior temporal gyrus (L) & -61 & -59 & 15 & -8.44 \\
\hline Middle temporal gyrus (R) & 33 & -67 & 27 & -8.43 \\
\hline Precuneus $(\mathrm{L})$ & -11 & -81 & 53 & -8.23 \\
\hline Inferior parietal lobule (L) & -43 & -71 & 45 & -8.21 \\
\hline Superior parietal lobule (R) & 41 & -57 & 57 & -7.22 \\
\hline Postcentral gyrus $(L)$ & -53 & -11 & 23 & -6.44 \\
\hline Anterior cingulate gyrus (L) & -1 & 21 & -3 & -6.13 \\
\hline Precentral gyrus (R) & 49 & -1 & 53 & -4.66 \\
\hline \multicolumn{5}{|l|}{ Beta } \\
\hline Superior temporal gyrus (L) & -59 & -61 & 15 & -11.9 \\
\hline Inferior temporal gyrus (L) & -47 & -65 & -5 & -11.5 \\
\hline Middle occipital gyrus (L) & -25 & -75 & 5 & -11.3 \\
\hline Fusiform gyrus (R) & 23 & -59 & -13 & -10.5 \\
\hline Middle occipital gyrus (R) & 27 & -75 & 11 & -10.2 \\
\hline \multicolumn{5}{|l|}{ Low gamma } \\
\hline Inferior frontal gyrus (R) & 31 & 31 & 7 & 9.52 \\
\hline Superior temporal gyrus (R) & 61 & -57 & 19 & 6.10 \\
\hline Middle temporal gyrus (L) & -65 & -55 & 5 & 5.64 \\
\hline Cuneus (L) & -3 & -91 & 21 & 4.10 \\
\hline \multicolumn{5}{|l|}{ High gamma } \\
\hline Superior parietal lobule (L) & -7 & -73 & 59 & 15.6 \\
\hline Precuneus (R) & 13 & -71 & 63 & 15.5 \\
\hline Anterior cingulate gyrus (R) & 17 & 37 & 11 & 13.2 \\
\hline Cingulate gyrus (R) & 17 & -11 & 43 & 13.1 \\
\hline Anterior cingulate gyrus (L) & -23 & 25 & 15 & 13.1 \\
\hline Cuneus (R) & 13 & -99 & -7 & 9.27 \\
\hline Inferior occipital gyrus (L) & -39 & -85 & -17 & 8.03 \\
\hline
\end{tabular}

due to peripheral facial electromyographic activity. Additionally, we found no differences in pre/postscan head position, which could explain the differences (Wilcoxon test, $p=0.36$, median ketamine $=2.2 \mathrm{~mm}$, median placebo $=1.9 \mathrm{~mm}$ ).

\section{Effective connectivity analysis}

We began our DCM analysis of frontoparietal effective connectivity by comparing three potential models of connectivity. In Model 1, the two sources (precuneus, prefrontal cortex) were 
connected by posterior-to-anterior feedforward connections and anterior-toposterior feedback connections (Fig. 1a, arrows $\mathrm{C}$ and $\mathrm{B}$ ). In Model 2, these connections were reversed such that feedforward connections were anteriorto-posterior and feedback connections posterior-to-anterior (Fig. 1 $a$, arrows A and D). Models 1 and 2 both represent hierarchically connected areas, whereas Model 3 contains fully reciprocated connectivity with all connections present (AD). After fitting the single trial data of all concatenated individuals we compared the log model evidence and determined that Model 3 was the winning model ( model evidences; Model $1=458$, Model $2=435$, Model $3=463$ ). The log- model evidence values take into account the complexity of models with different numbers of parameters. This complexity term is the Kullback-Leibler divergence between prior and posterior parameter space and takes account of effective degrees-of-freedom introduced by new parameters (Penny et al., 2010). The grand-averaged cross-spectral densities for both modeled and empirical data are displayed in Figure $6 a$; these show good fits of the models to the empirical data. As example data features in the crossconjugate space (Fig. 6b), beta band coherence and source lag appear altered with ketamine. The posterior estimates from the grand-average were then used to initialize parameter fits for individual spectra. A correlation (Fig. 6c) was observed between participants' self report of blissful state and the decrease in parietal gain $(\rho=-0.53, p=0.02)$, but not the other DCM parameters (all $p>0.05$ ). In terms of connectivity parameters, Wilcoxon signed rank tests showed significant modulation of the NMDA-mediated backward connectivity $\left(p=3.1 \mathrm{e}^{-6}\right)$, AMPA-mediated backward connectivity $(p=0.017)$, but not NMDA-mediated forward connectivity $(p>0.05)$ or AMPA-mediated forward connectivity $(p>0.05)$. A significant decrease in the gain of the parietal population was also found $\left(p=8.9 \mathrm{e}^{-6}\right)$, but no difference in the frontal population gain $(p>0.05$; Fig. 6d).

\section{Functional connectivity analysis}

Finally, we performed a functional connectivity analysis on the band limited source power envelopes (Fig. 7). A number of simple networks including visual parietal and motor networks were significantly altered by ketamine in the alpha and beta frequency bands. Although a number of frontoparietal networks were
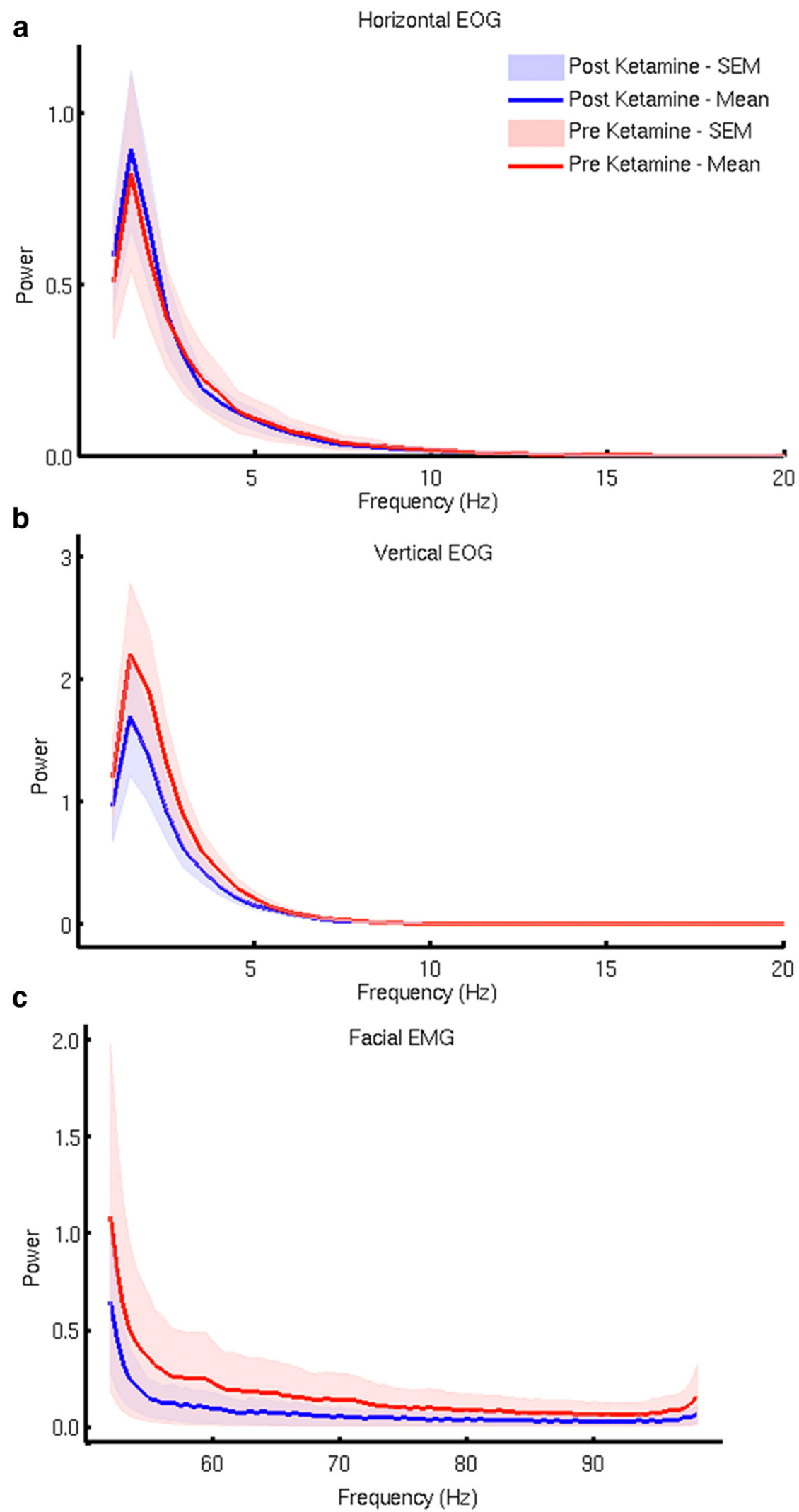

Figure 5. Spectral analysis of the vertical and horizontal EOGs and facial EMGs before and after ketamine infusion. Because of the location of frontal theta increases in the medial prefrontal cortex, we wished to confirm that theta differences were not potentially due to differential eye movements between the conditions. Spectral analysis of the two EOG channels $(\boldsymbol{a}, \boldsymbol{b})$ revealed no difference between ketamine and placebo that could account for the increase in medial prefrontal cortex theta power. Similarly, because of the increase in gamma-band amplitudes in the MEG data, we found no evidence from this analysis (c) that these were due to an increase in facial EMG activity. 
a

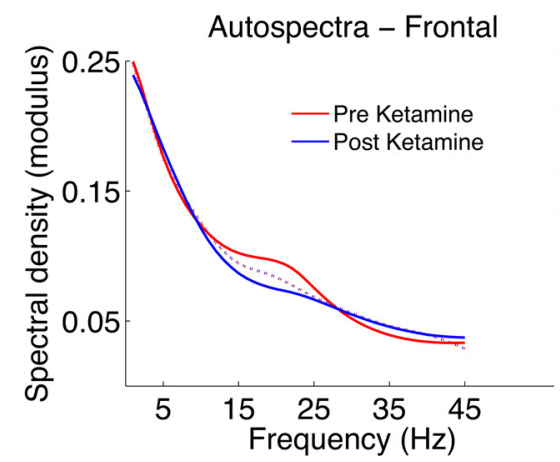

b

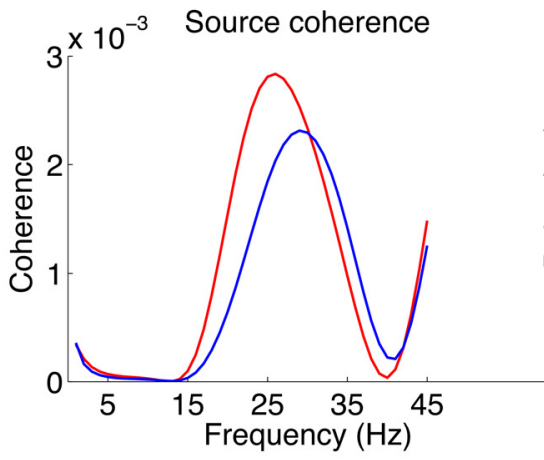

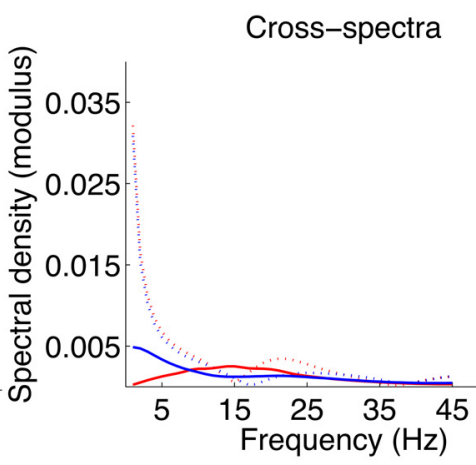

Phase Delay

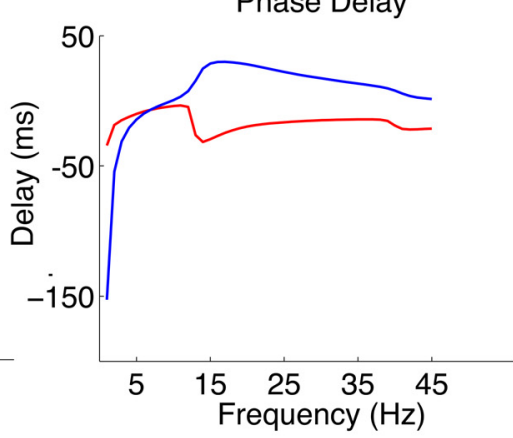

Autospectra - Parietal

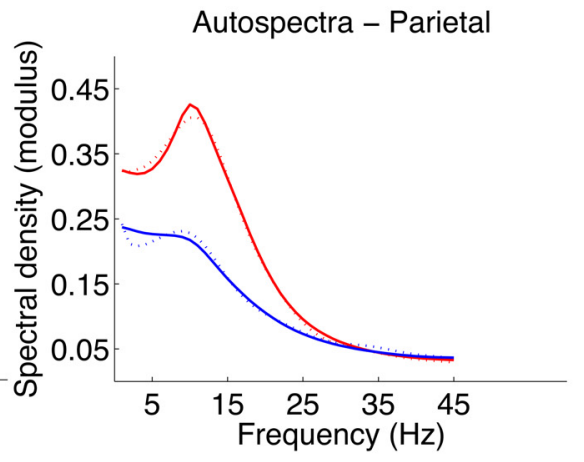

d

Parameter modulations by ketamine

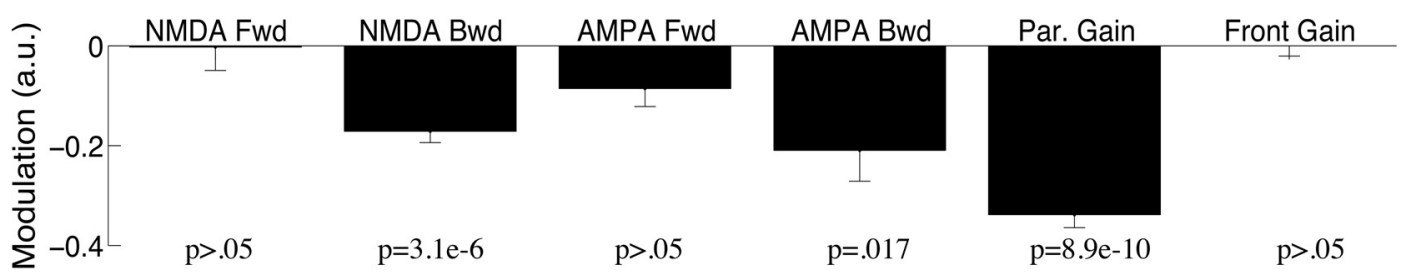

Figure 6. $\quad \boldsymbol{a}$, Cross-spectral densities and model fits. Grand-averaged data ( $n=19)$ were computed for preketamine (solid black line) and postketamine (solid blue line) for the frequency range 1- $45 \mathrm{~Hz}$. Grand-averaged DCM model fits are represented by the dashed lines. $\boldsymbol{b}$, Example source space data features including frequency dependence coherence and time-lag between sources. c, Correlation of participants' rating of "blissful experience" and posterior gain modulation. Participants' ratings of "bliss" were computed from 5D-ASC subscales as devised by Studerus et al. (2010) and scaled to a percentage of the maximum possible score. A significant negative correlation was found between participants ratings of bliss and gain reduction in the parietal lobe. Spearman correlation tests were used to reduce outlier effects and control for non-normality in the data. $\boldsymbol{d}$, Parameters modulations by ketamine for each of the modulation parameters (A-F). Sign rank tests were used to reduce outlier effects and control for non-normality in the data. A Bonferroni adjustment of six to the presented significance values to control the familywise error rate ( 6 parameters). Error bars are the standard error of the mean.

identified in the lower frequency bands, we did not observe modulation of these by ketamine, even if we removed the conservative Bonferroni correction.

\section{Experiment 2}

\section{Pharmacodynamics}

We temporally mapped the pharmacodynamics effects in a further set of participants. Notably, the subjective effects of ketamine had abated $\sim 40$ min after the infusion had been ceased (Fig. 8c). The three areas and frequency bands chosen for further analysis each displayed distinct temporal dynamics, with theta band showing only a transient increase in power. Similar to the psychological effects, the increase in posterior gamma band power ceased $\sim 40 \mathrm{~min}$ after infusion had ceased. Alpha power, however (Fig. 8f), showed sustained power decreases that had still not returned to baseline $50 \mathrm{~min}$ after the infusion. In these data, we applied the same connectivity model (Model 3) that we used to track the temporal dynamics of effective connectivity changes. The effects on connectivity in these independent data were very similar to those in Experiment 1 . The AMPA-mediated connectivity and the parietal gain were still decreased $50 \mathrm{~min}$ after the termination of infusion (Fig. 9). To examine potential relationships between the DCM parameter time courses and the power envelopes (three power envelopes, 6 DCM parameters, Bonferroni correction $=18$ ) we used a general linear model analysis controlling for random subject effects. We found that the posterior gain parameter tended to follow the alpha envelope $(t=$ $\left.10.8, p=1 \mathrm{e}^{-11}\right)$, whereas the anterior gain followed the theta envelope $(t=3.6, p=0.014)$. Notably, the connectivity parameters did not track the envelope parameters (all $p>0.05$ ) even when uncorrected for multiple comparisons.

\section{Discussion}

In these experiments, we found that subanesthetic infusions of ketamine caused a decrease in posterior alpha-band power, an increase in prefrontal theta power, as well as widespread increases in gamma-band power. These oscillatory changes were accompanied by temporally sustained reductions in frontoparietal effective connectivity, which we assessed using dynamic causal modeling. Previous studies have investigated the anesthetic effects on the EEG of ketamine-induced unconsciousness and have shown that $2 \mathrm{mg} / \mathrm{kg}$ of ketamine also causes reductions in di- 

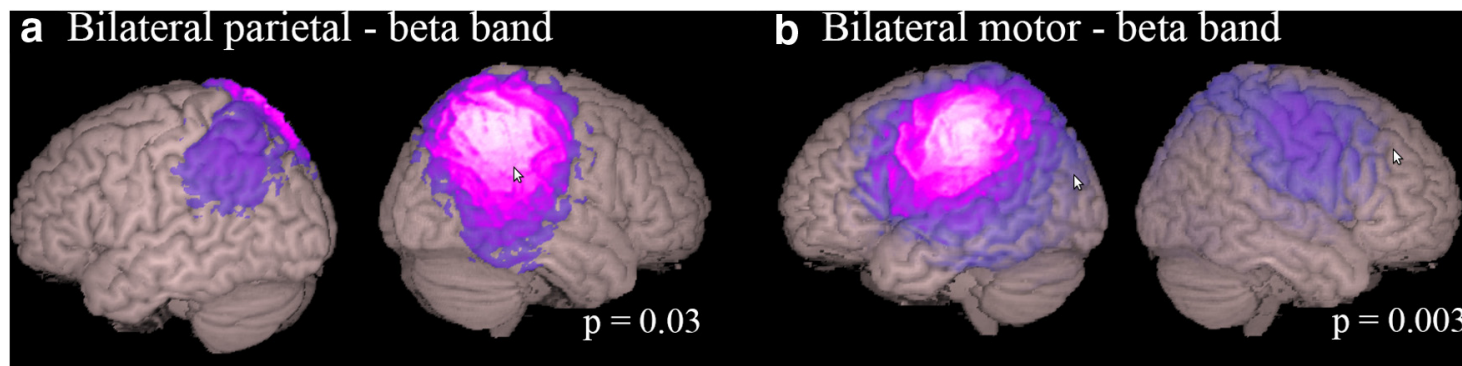

c Bilateral occipital - alpha band
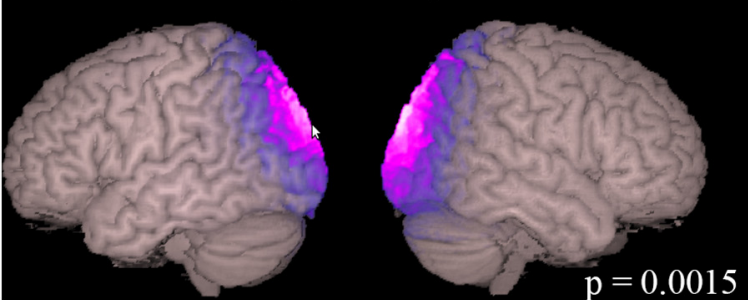

Figure 7. Results of functional connectivity analyses showing the localization of MEG resting-state network significantly altered by ketamine, which consisted of bilateral parietal ( $\boldsymbol{a}$ ), motor ( $\boldsymbol{b}$ ), and occipital (c) networks. Images show absolute ICA weights (in a.u.) thresholded at a value of 0.2 . All modulations were decreases in the activity of the networks derived by independent component analysis of the band-power limited source waveforms. Although frontoparietal networks were identified in delta, theta, alpha, and beta frequency bands, these networks were not significantly modulated by ketamine. A Bonferroni adjustment of 15 (15 components per frequency band) is applied to the presented significance values.

\section{a Infusion Protocol}

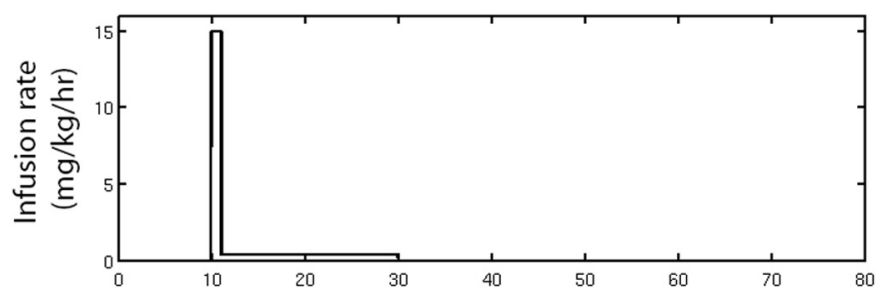

b Estimated plasma concentration

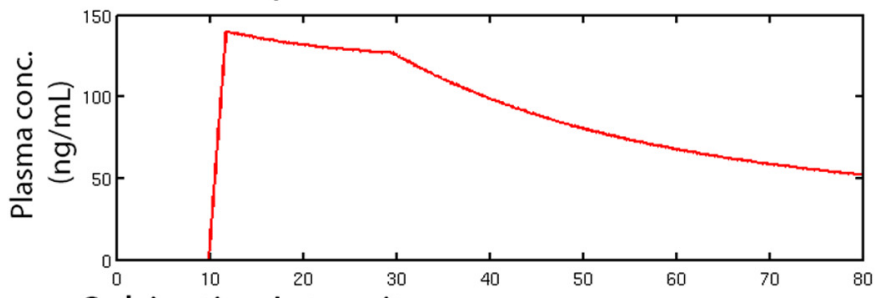

c Subjective Intensity

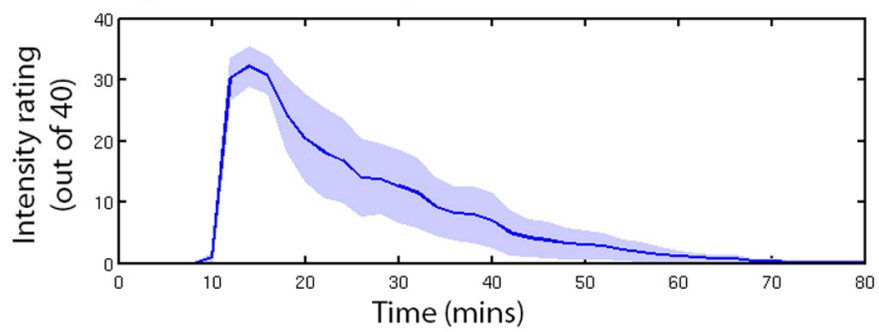

d Posterior gamma $(51-99 \mathrm{~Hz})$

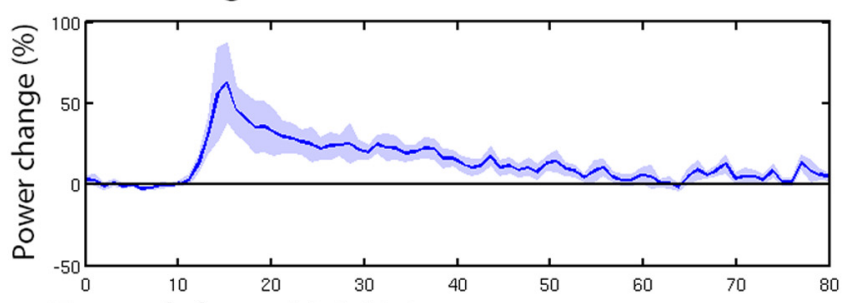

e Frontal theta $(4-8 \mathrm{~Hz})$

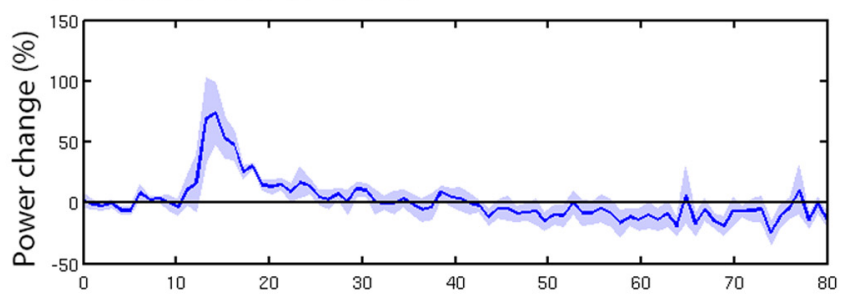

f Posterior alpha $(8-13 \mathrm{~Hz})$

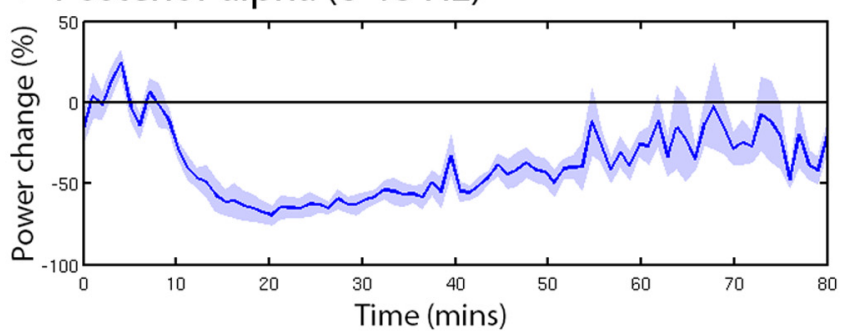

Figure 8. Time-course dynamics for data collected in Experiment 2 ( 80 min resting state). $\boldsymbol{a}$, The infusion protocol used is illustrated starting with an initial bolus followed by slow infusion. $\boldsymbol{b}$, Estimated time course plasma concentration using the two-compartment model of Clements and Nimmo (1981). The pharmacokinetic parameters for this model were originally obtained using participants of a similar age/sex/health status to ours. $\boldsymbol{c}$, Subjective ratings of drug "effect intensity" given by participants at 2 min intervals. $\boldsymbol{d}$ - $\boldsymbol{f}$, Time courses of band-limited virtual sensor power for specific time-frequency regions of interest computed as percentage change from the preinfusion time period ( $0-10$ min). Shaded areas represent the standard error of the mean.

rected frontoparietal connectivity (Lee et al., 2013; Blain-Moraes et al., 2014). Our data demonstrate these reductions occur at doses well below those needed to induce loss of consciousness, suggesting that reduced frontoparietal connectivity need not be associated with loss of consciousness (Boly et al., 2012). In contrast to EEG/MEG connectivity studies of subanesthetic ketamine doses, fMRI studies have shown mixed results with regard to functional connectivity. One fMRI study using a similar dosing 
a NMDA Forward connection

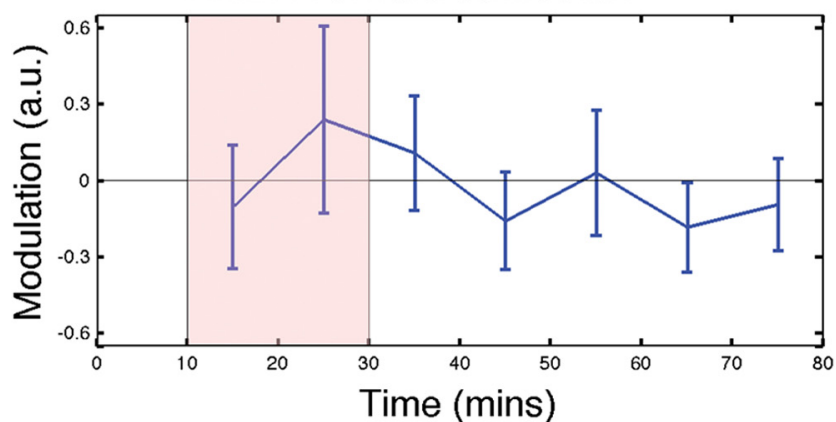

c AMPA Forward connection

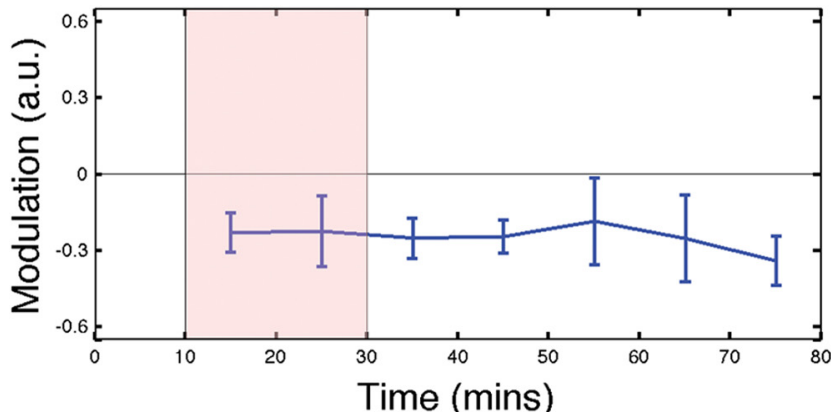

e Parietal Gain

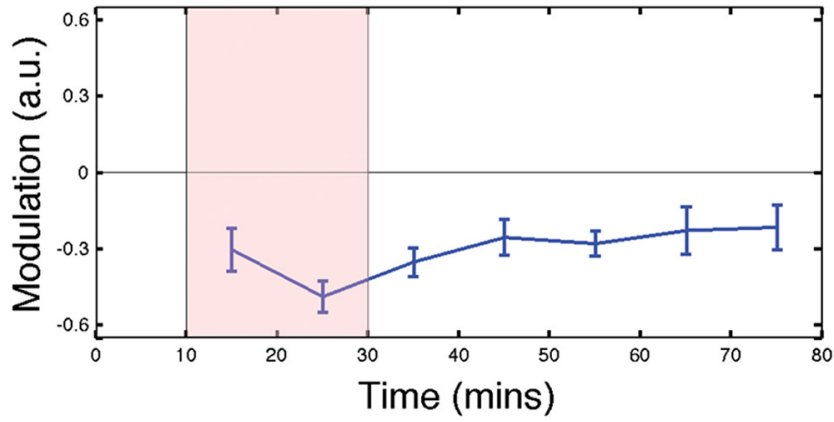

b NMDA Backward connection

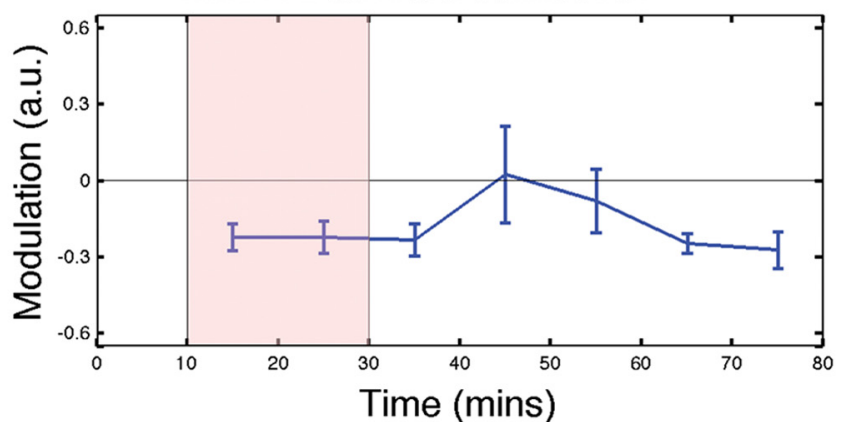

d AMPA Backward connection

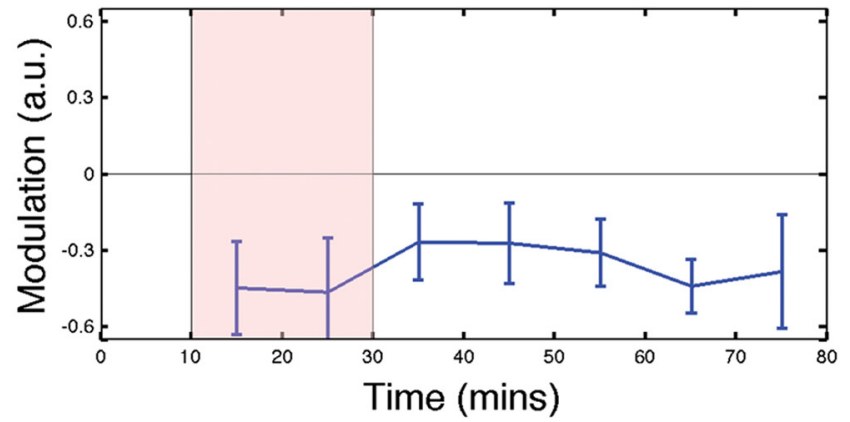

f

Frontal Gain

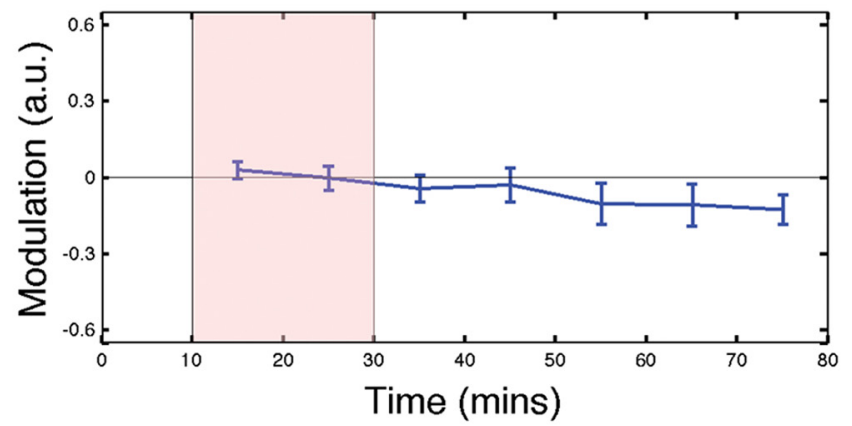

Figure 9. Time course of parameter modulations for the six DCM (a-f) parameters tested in Experiment 2 (Fig. 1). The time period of ketamine infusion is shaded red. The parameters were generated by comparing the spectra of the preinfusion window with the postinfusion period binned into 10 min windows. Error bars are the standard error of the mean.

protocol to ours reported globally increased hyperconnectivity (Driesen et al., 2013). Similarly, a study in rats found dosedependent increases in hippocampal-prefrontal cortex connectivity following subanesthetic ketamine infusion (Gass et al., 2014). Conversely, a different study reported increases in connectivity in visual networks but decreases in affective networks (Niesters et al., 2012). Finally, others have reported decreases in functional connectivity in the default mode, cognitive control, and affective networks $24 \mathrm{~h}$ after ketamine infusion (Scheidegger et al., 2012). It is important to bear in mind that fMRI measures of functional connectivity are highly dependent on hemodynamic and vascular factors (Murphy et al., 2013). At subanesthetic doses, ketamine is well known to cause relatively large systemic changes in blood pressure and heart rate (Fig. 2; Pandit et al., 1980). Both of these factors can confound fMRI resting state studies (Murphy et al., 2013), which makes it surprising that few fMRI studies of ketamine have attempted to apply physiological correction methods. Alternatively, the differences in results between $\mathrm{AMRI}$ and EEG/MEG studies may be due to the fact that fMRI measures are potentially sensitive to a more diverse range of neural processes, whereas MEG/EEG are highly tuned to measur- ing the summation of synchronized postsynaptic potentials at pyramidal cells (Lopes da Silva, 2011).

In the present studies, we observed that the reduction in parietal gain was correlated with participants' rating of "blissful state". This gain parameter is a "lumped" parameter and could potentially reflect either the intrinsic action of ketamine at NMDA receptors within the parietal pyramidal cell ensemble, or many of the non-NMDA affinities of ketamine, such as antagonism of HCN channels (Chen et al., 2009; see Introduction). Regardless, the correlation of parietal gain changes with positive subjective experiences is somewhat similar to the results of our previous study, where decreases in parietal activity caused by the mixed $5 \mathrm{HT}_{2 \mathrm{~A}}$ receptor agonist psilocybin were correlated with increases in participants' ratings of ego dissolution and magical thinking (Muthukumaraswamy et al., 2013). Although many studies have focused on the psychotomimetic properties of ketamine, fewer have focused on the euphoric feelings that people experience during ketamine sedation. At subanesthetic doses, most participants report that they experience feelings of euphoria and that the hallucinations induced are generally pleasant; they also report that they would be happy to repeat the same treat- 
ment again (Pandit et al., 1980). Caution is advised in interpreting these results, however, because of self-selection in the study populations.

The pharmacodynamics results that we report here are consistent with previous EEG anesthesia studies, which have shown similar transient increases in theta immediately after ketamine infusion with more sustained posterior alpha-band decreases (Kochs et al., 1996). Further, the increase in gamma-band activity and its time course, here in humans, is strikingly similar to the increases in rat EEG with ketamine and MK-801(Pinault, 2008; Wood et al., 2012). Importantly, the effects we observe are present in the resting MEG/EEG, whereas some previous descriptions of ketamine gamma/delta frequency-changes are based on evoked response paradigms (Hong et al., 2010) or task-induced oscillatory changes (Shaw et al., 2015), which may have different generative mechanisms and are limited mostly to sensory cortices. This widespread "aberrant" (Pinault, 2008) gamma-band activity in the neocortex could potentially be a mechanism that drives the decrease in interpopulation connectivity. Increased gamma-band activity may represent pharmacologicallyinduced noise at pyramidal cells assemblies, which disrupts information processing and the ability of these cell assemblies to send and/or receive long-range signals efficiently (Moran et al., 2015).

It is notable in this experiment that significant modulations of frontoparietal effective connectivity were observed using the DCM approach, however, no modulations of frontoparietal functional connectivity were observed when using a technique based on bandpass power correlations (Brookes et al., 2011). This probably reflects different signal elements to which each technique is sensitive. In particular, in the computation of the bandpass power envelopes, all phase information from the signals is discarded and further the envelopes are usually heavily down-sampled. DCM for steady-state responses considers a broader scope of data features including phase (cross-spectral density) information. In Experiment 2, the DCM connectivity parameters did not track the time course of the amplitude envelopes, whereas the gain parameters did. This suggests that the connectivity parameters are independent of signal-to-noise ratio (Friston, 2011), which can confound some estimates of functional connectivity, such as phase locking factors (Muthukumaraswamy and Singh, 2011).

The ability of ketamine to reduce resting state effective connectivity has potentially important implications for the treatment of depression. Sheline et al. (2009) have demonstrated that the default mode network is overactive in major depression, and that it has reduced ability to "switch off" during task performance. Similarly, increased resting state functional connectivity in the subgenual cingulate and thalamus is increased in depression, which is correlated with the length of depressive episode (Greicius et al., 2007). Overactivity of the default network in depression is correlated with behavioral measures of rumination and brooding (Berman et al., 2011). Quantitative electroencephalography has also shown increased occipital-to-parietal coherence in the alpha and theta frequency bands in major depressive disorder (Leuchter et al., 2012). Further, following treatment with SSRI's, functional connectivity of the default mode network is reduced; this effect correlates with a reduction in depressive symptoms (Wang et al., 2015). Together, these results suggest that, at least in a subset of patients, the major depressive disorder is characterized by hyperconnectivity of the default mode network. The rapid therapeutic action of ketamine may be due to its ability to reduce this hyperconnectivity, a hypothesis that requires testing.

Current molecular models of depression based largely on animal data have emphasized the importance of synaptogenic mechanisms in mediating the antidepressant effects of ketamine
(Duman et al., 2012). In these models, blockade of NMDA receptors by ketamine causes increased activity at AMPA receptors, which causes increased activity of the mTOR signaling pathway, which in turn triggers synthesis of synaptic proteins, such as Arc and synapsin. Indeed, low doses of ketamine cause rapid increases in spine numbers on layer $\mathrm{V}$ pyramidal cells of the prefrontal cortex (Li et al., 2010). However, it could be argued that activation of the mTOR pathway may not be sufficient as an explanation of the antidepressant effects of ketamine. It is well known that a number of drugs of abuse that do not have antidepressant effects, including THC, morphine, alcohol, and cocaine, also activate the mTOR signaling pathway (Neasta et al., 2014). Indeed activation of the mTOR pathways may be a mechanism underlying addictive behaviors (Neasta et al., 2014), but given its general role in mediating long-term plasticity (Costa-Mattioli and Monteggia, 2013), it may serve the more general function of adapting the brain to remaining in its current dynamical state. We therefore speculatively propose that the antidepressant actions of ketamine may depend on both its ability to reduce hyperconnectivity and its activation of synaptogenic mechanisms. This can cause long-term stabilization of these changes allowing brain networks to restabilize in a different part of state-space.

\section{References}

Andrews-Hanna JR, Reidler JS, Sepulcre J, Poulin R, Buckner RL (2010) Functional-anatomic fractionation of the brain's default network. Neuron 65:550-562. CrossRef Medline

Autry AE, Adachi M, Nosyreva E, Na ES, Los MF, Cheng PF, Kavalali ET, Monteggia LM (2011) NMDA receptor blockade at rest triggers rapid behavioural antidepressant responses. Nature 475:91-95. CrossRef Medline

Bastiaansen MC, Knösche TR (2000) Tangential derivative mapping of axial MEG applied to event-related desynchronization research. Clin Neurophysiol 111:1300-1305. CrossRef Medline

Bergman SA (1999) Ketamine: review of its pharmacology and its use in pediatric anesthesia. Anesth Prog 46:10-20. Medline

Berman MG, Peltier S, Nee DE, Kross E, Deldin PJ, Jonides J (2011) Depression, rumination and the default network. Soc Cogn Affect Neurosci 6:548-555. CrossRef Medline

Berman RM, Cappiello A, Anand A, Oren DA, Heninger GR, Charney DS, Krystal JH (2000) Antidepressant effects of ketamine in depressed patients. Biol Psychiatry 47:351-354. CrossRef Medline

Blain-Moraes S, Lee U, Ku S, Noh G, Mashour GA (2014) Electroencephalographic effects of ketamine on power, cross-frequency coupling, and connectivity in the alpha bandwidth. Front Syst Neurosci 8:114. CrossRef Medline

Boly M, Moran R, Murphy M, Boveroux P, Bruno MA, Noirhomme Q, Ledoux D, Bonhomme V, Brichant JF, Tononi G, Laureys S, Friston K (2012) Connectivity changes underlying spectral EEG changes during propofol-induced loss of consciousness. J Neurosci 32:7082-7090. CrossRef Medline

Brookes MJ, Woolrich M, Luckhoo H, Price D, Hale JR, Stephenson MC, Barnes GR, Smith SM, Morris PG (2011) Investigating the electrophysiological basis of resting state networks using magnetoencephalography. Proc Natl Acad Sci U S A 108:16783-16788. CrossRef Medline

Chen X, Shu S, Bayliss DA (2009) HCN1 channel subunits are a molecular substrate for hypnotic actions of ketamine. J Neurosci 29:600-609. CrossRef Medline

Clements JA, Nimmo WS (1981) Pharmacokinetics and analgesic effect of ketamine in man. Br J Anaesth 53:27-30. CrossRef Medline

Cornwell BR, Salvadore G, Furey M, Marquardt CA, Brutsche NE, Grillon C, Zarate CA Jr (2012) Synaptic potentiation is critical for rapid antidepressant response to ketamine in treatment-resistant major depression. Biol Psychiatry 72:555-561. CrossRef Medline

Costa-Mattioli M, Monteggia LM (2013) mTOR complexes in neurodevelopmental and neuropsychiatric disorders. Nat Neurosci 16:1537-1543. CrossRef Medline

David O, Kiebel SJ, Harrison LM, Mattout J, Kilner JM, Friston KJ (2006) Dynamic causal modeling of evoked responses in EEG and MEG. Neuroimage 30:1255-1272. CrossRef Medline 
Delorme A, Makeig S (2004) EEGLAB: an open source toolbox for analysis of single-trial EEG dynamics including independent component analysis. J Neurosci Methods 134:9-21. CrossRef Medline

Dittrich A (1998) The standardized psychometric assessment of altered states of consciousness (ASCs) in humans. Pharmacopsychiatry 31:80-84. CrossRef Medline

Driesen NR, McCarthy G, Bhagwagar Z, Bloch M, Calhoun V, D'Souza DC, Gueorguieva R, He G, Ramachandran R, Suckow RF, Anticevic A, Morgan PT, Krystal JH (2013) Relationship of resting brain hyperconnectivity and schizophrenia-like symptoms produced by the NMDA receptor antagonist ketamine in humans. Mol Psychiatry 18: 1199-1204. CrossRef Medline

Duman RS, Li N, Liu RJ, Duric V, Aghajanian G (2012) Signaling pathways underlying the rapid antidepressant actions of ketamine. Neuropharmacology 62:35-41. CrossRef Medline

Durstewitz D, Seamans JK, Sejnowski TJ (2000) Neurocomputational models of working memory. Nat Neurosci 3:1184-1191. CrossRef Medline

Felleman DJ, Van Essen DC (1991) Distributed hierarchical processing in the primate cerebral cortex. Cereb Cortex 1:1-47. CrossRef Medline

Friston KJ (2011) Functional and effective connectivity: a review. Brain Connect 1:13-36. CrossRef Medline

Friston KJ, Bastos A, Litvak V, Stephan KE, Fries P, Moran RJ (2012) DCM for complex-valued data: cross-spectra, coherence and phase-delays. Neuroimage 59:439-455. CrossRef Medline

Friston K, Mattout J, Trujillo-Barreto N, Ashburner J, Penny W (2007) Variational free energy and the Laplace approximation. Neuroimage 34: 220-234. CrossRef Medline

Gass N, Schwarz AJ, Sartorius A, Schenker E, Risterucci C, Spedding M, Zheng L, Meyer-Lindenberg A, Weber-Fahr W (2014) Sub-anesthetic ketamine modulates intrinsic BOLD connectivity within the hippocampal-prefrontal circuit in the rat. Neuropsychopharmacology 39:895-906. CrossRef Medline

Greicius MD, Flores BH, Menon V, Glover GH, Solvason HB, Kenna H, Reiss AL, Schatzberg AF (2007) Resting-state functional connectivity in major depression: abnormally increased contributions from subgenual cingulate cortex and thalamus. Biol Psychiatry 62:429-437. CrossRef Medline

Hall EL, Woolrich MW, Thomaz CE, Morris PG, Brookes MJ (2013) Using variance information in magnetoencephalography measures of functional connectivity. Neuroimage 67:203-212. CrossRef Medline

Hong LE, Summerfelt A, Buchanan RW, O'Donnell P, Thaker GK, Weiler MA, Lahti AC (2010) Gamma and delta neural oscillations and association with clinical symptoms under subanesthetic ketamine. Neuropsychopharmacology 35:632-640. CrossRef Medline

Huang MX, Mosher JC, Leahy RM (1999) A sensor-weighted overlappingsphere head model and exhaustive head model comparison for MEG. Phys Med Biol 44:423-440. CrossRef Medline

Hyvärinen A, Oja E (2000) Independent component analysis: algorithms and applications. Neural Netw 13:411-430. CrossRef Medline

Kobayashi Y, Amaral DG (2003) Macaque monkey retrosplenial cortex: II. Cortical afferents. J Comp Neurol 466:48-79. CrossRef Medline

Kobayashi Y, Amaral DG (2007) Macaque monkey retrosplenial cortex: III. Cortical efferents. J Comp Neurol 502:810-833. CrossRef Medline

Kochs E, Scharein E, Möllenberg O, Bromm B, Schulte am Esch J (1996) Analgesic efficacy of low-dose ketamine: somatosensory-evoked responses in relation to subjective pain ratings. Anesthesiology 85:304-314. CrossRef Medline

Krystal JH, Sanacora G, Duman RS (2013) Rapid-acting glutamatergic antidepressants: the path to ketamine and beyond. Biol Psychiatry 73:11331141. CrossRef Medline

Lee U, Ku S, Noh G, Baek S, Choi B, Mashour GA (2013) Disruption of frontal-parietal communication by ketamine, propofol, and sevoflurane. Anesthesiology 118:1264-1275. CrossRef Medline

Leuchter AF, Cook IA, Hunter AM, Cai C, Horvath S (2012) Resting-state quantitative electroencephalography reveals increased neurophysiologic connectivity in depression. PloS One 7:e32508. CrossRef Medline

Li N, Lee B, Liu RJ, Banasr M, Dwyer JM, Iwata M, Li XY, Aghajanian G, Duman RS (2010) mTOR-dependent synapse formation underlies the rapid antidepressant effects of NMDA antagonists. Science 329:959-964. CrossRef Medline

Lopes da Silva F (2011) Biophysical aspects of EEG and magnetoencephalogram generation. In: Niedermeyer's electroencephalography, Ed 6 (Schomer DL, Lopes da Silva F, eds). Philadelphia: Lippincott Williams and Wilkins.
Maris E, Oostenveld R (2007) Nonparametric statistical testing of EEG- and MEG-data. J Neurosci Methods 164:177-190. CrossRef Medline

Moran RJ, Stephan KE, Dolan RJ, Friston KJ (2011a) Consistent spectral predictors for dynamic causal models of steady-state responses. Neuroimage 55:1694-1708. CrossRef Medline

Moran RJ, Symmonds M, Stephan KE, Friston KJ, Dolan RJ (2011b) An in vivo assay of synaptic function mediating human cognition. Curr Biol 21:1320-1325. CrossRef Medline

Moran RJ, Jones MW, Blockeel AJ, Adams RA, Stephan KE, Friston KJ (2015) Losing control under ketamine: suppressed cortico-hippocampal drive following acute ketamine in rats. Neuropsychopharmacology 40 : 268-277. CrossRef Medline

Murphy K, Birn RM, Bandettini PA (2013) Resting-state fMRI confounds and cleanup. Neuroimage 80:349-359. CrossRef Medline

Murrough JW, Iosifescu DV, Chang LC, Al Jurdi RK, Green CE, Perez AM, Iqbal S, Pillemer S, Foulkes A, Shah A, Charney DS, Mathew SJ (2013) Antidepressant efficacy of ketamine in treatment-resistant major depression: a two-site randomized controlled trial. Am J Psychiatry 170:11341142. CrossRef Medline

Muthukumaraswamy SD (2013) High-frequency brain activity and muscle artifacts in MEG/EEG: a review and recommendations. Front Hum Neurosci 7:138. CrossRef Medline

Muthukumaraswamy SD, Singh KD (2011) A cautionary note on the interpretation of phase-locking estimates with concurrent changes in power. Clin Neurophysiol 122:2324-2325. CrossRef Medline

Muthukumaraswamy SD, Carhart-Harris RL, Moran RJ, Brookes MJ, Williams TM, Errtizoe D, Sessa B, Papadopoulos A, Bolstridge M, Singh KD, Feilding A, Friston KJ, Nutt DJ (2013) Broadband cortical desynchronization underlies the human psychedelic state. J Neurosci 33:15171-15183. CrossRef Medline

Nagele P, Duma A, Kopec M, Gebara MA, Parsoei A, Walker M, Janski A, Panagopoulos VN, Cristancho P, Miller JP, Zorumski CF, Conway CR (2015) Nitrous oxide for treatment-resistant major depression: a proofof-concept trial. Biol Psychiatry 78:10-18. CrossRef Medline

Neasta J, Barak S, Hamida SB, Ron D (2014) mTOR complex 1: a key player in neuroadaptations induced by drugs of abuse. J Neurochem 130:172184. CrossRef Medline

Nichols TE, Holmes AP (2002) Nonparametric permutation tests for functional neuroimaging: a primer with examples. Hum Brain Mapp 15:1-25. CrossRef Medline

Niesters M, Khalili-Mahani N, Martini C, Aarts L, van Gerven J, van Buchem MA, Dahan A, Rombouts S (2012) Effect of subanesthetic ketamine on intrinsic functional brain connectivity: a placebo-controlled functional magnetic resonance imaging study in healthy male volunteers. Anesthesiology 117:868-877. CrossRef Medline

Oostenveld R, Fries P, Maris E, Schoffelen JM (2011) FieldTrip: open source software for advanced analysis of MEG, EEG, and invasive electrophysiological data. Comput Intell Neurosci 2011:156869. CrossRef Medline

Pandit SK, Kothary SP, Kumar SM (1980) Low dose intravenous infusion technique with ketamine: amnesic, analgesic and sedative effects in human volunteers. Anaesthesia 35:669-675. CrossRef Medline

Penny WD, Stephan KE, Daunizeau J, Rosa MJ, Friston KJ, Schofield TM, Leff AP (2010) Comparing families of dynamic causal models. PLoS Comput Biol 6:e1000709. CrossRef Medline

Pinault D (2008) $\mathrm{N}$-methyl d-aspartate receptor antagonists ketamine and MK-801 induce wake-related aberrant gamma oscillations in the rat neocortex. Biol Psychiatry 63:730-735. CrossRef Medline

Posner J, Hellerstein DJ, Gat I, Mechling A, Klahr K, Wang Z, McGrath PJ, Stewart JW, Peterson BS (2013) Antidepressants normalize the default mode network in patients with dysthymia. JAMA Psychiatry 70:373-382. CrossRef Medline

Robinson SE, Vrba J (1999) Functional neuroimaging by synthetic aperture magnetometry (SAM). In: Recent advances in biomagnetism (Yoshimoto T, Kotani M, Kuriki S, Karibe H, Nakasato N, eds), pp 302-305. Sendai: Tohoku UP.

Rush AJ (2013) Ketamine for treatment-resistant depression: ready or not for clinical use? Am J Psychiatry 170:1079-1081. CrossRef Medline

Salvadore G, Cornwell BR, Colon-Rosario V, Coppola R, Grillon C, Zarate CA Jr, Manji HK (2009) Increased anterior cingulate cortical activity in response to fearful faces: a neurophysiological biomarker that predicts rapid antidepressant response to ketamine. Biol Psychiatry 65:289-295. CrossRef Medline

Salvadore G, Cornwell BR, Sambataro F, Latov D, Colon-Rosario V, Carver F, 
Holroyd T, DiazGranados N, Machado-Vieira R, Grillon C, Drevets WC, Zarate CA Jr (2010) Anterior cingulate desynchronization and functional connectivity with the amygdala during a working memory task predict rapid antidepressant response to ketamine. Neuropsychopharmacology 35:1415-1422. CrossRef Medline

Sanacora G, Smith MA, Pathak S, Su HL, Boeijinga PH, McCarthy DJ, Quirk MC (2014) Lanicemine: a low-trapping NMDA channel blocker produces sustained antidepressant efficacy with minimal psychotomimetic adverse effects. Mol Psychiatry 19:978-985. CrossRef Medline

Scheidegger M, Walter M, Lehmann M, Metzger C, Grimm S, Boeker H, Boesiger P, Henning A, Seifritz E (2012) Ketamine decreases resting state functional network connectivity in healthy subjects: implications for antidepressant drug action. PLoS One 7:e44799. CrossRef Medline

Shaw AD, Saxena N, Jackson L, Hall JE, Singh KD, Muthukumaraswamy SD (2015) Ketamine amplifies induced gamma frequency oscillations in the human cerebral cortex. Eur Neuropsychopharmacology. Advance online publication. CrossRef Medline

Sheline YI, Barch DM, Price JL, Rundle MM, Vaishnavi SN, Snyder AZ, Mintun MA, Wang S, Coalson RS, Raichle ME (2009) The default mode network and self-referential processes in depression. Proc Natl Acad Sci U S A 106:1942-1947. CrossRef Medline

Smith SM (2002) Fast robust automated brain extraction. Hum Brain Mapp 17:143-155. CrossRef Medline
Stahl SM (2013) Mechanism of action of ketamine. CNS Spectr 18:171-174. CrossRef Medline

Studerus E, Gamma A, Vollenweider FX (2010) Psychometric evaluation of the altered states of consciousness rating scale (OAV). PloS One 5:e12412. CrossRef Medline

Vrba J, Robinson SE (2001) Signal processing in magnetoencephalography. Methods 25:249-271. CrossRef Medline

Wang L, Xia M, Li K, Zeng Y, Su Y, Dai W, Zhang Q, Jin Z, Mitchell PB, Yu X, He Y, Si T (2015) The effects of antidepressant treatment on restingstate functional brain networks in patients with major depressive disorder. Hum Brain Mapp 36:768-778. CrossRef Medline

Wood J, Kim Y, Moghaddam B (2012) Disruption of prefrontal cortex large scale neuronal activity by different classes of psychotomimetic drugs. J Neurosci 32:3022-3031. CrossRef Medline

Zarate CA Jr, Singh JB, Quiroz JA, De Jesus G, Denicoff KK, Luckenbaugh DA, Manji HK, Charney DS (2006a) A double-blind, placebocontrolled study of memantine in the treatment of major depression. Am J Psychiatry 163:153-155. CrossRef Medline

Zarate CA Jr, Singh JB, Carlson PJ, Brutsche NE, Ameli R, Luckenbaugh DA, Charney DS, Manji HK (2006b) A randomized trial of an $N$-methyl-Daspartate antagonist in treatment-resistant major depression. Arch Gen Psychiatry 63:856-864. CrossRef Medline 